tabulated, critically assessed. The various types of behavioural experiment are carefully explained and for the reader without experience of the psychological literature this is an outstandingly good introduction. The conclusion the authors reach at the end of this exhaustive survey is that, in general, and as the theory would predict, behavioural deficits in hippocampal animals only emerge in tasks which the intact animal solves using place hypotheses; even then the hippocampal animal may be able to compensate by using alternative route-type strategies. This distinction between the use of place hypotheses in normal animals and the compensatory use of route hypotheses in hippocampal animals brings a considerable degree of order to a literature rich in apparently contradictory results. Nevertheless, doubts remain. During the course of their review a barrage of analytical ingenuity is directed against experiments which do not at first sight fit the prediction of the theory. The effect of this is ultimately to raise doubts in the reader's mind about the ability of any experiment, whatever its results, to furnish convincing evidence against the theory.

The final section is taken up with a discussion of the amnesia which results from hippocampal lesions in humans. This is a controversial area with no general agreement about the extent to which amnesia is a failure of recall rather than a failure of storage. O'Keefe and Nadel propose that the human hippocampus is reserved for a context-dependent memory system, having a spatial component equivalent to a cognitive map, which is located in the right hippocampus and a verbal component responsible for memory of connected discourse or narrative, which is represented in the form of a semantic map in the left hippocampus. They conclude that while the use of strategies designed to assist recall can often improve the performance of amnesics in contextfree tasks, such as memorising word lists, this is not the case for context-dependent memories: here the loss of memory is total and irrecoverable.

Both authors were at one time students of D.O. Hebb, and their book, though it lacks the stylistic charm of Hebb's monograph Organization of Behaviour, follows the same tradition in its attempt to fuse neurobiological and behavioural data into a unified theory of function. The verdict on the theory must, at the moment, be 'unproven'. But whether or not the theory survives, O'Keefe and Nadel have in this book provided a solid basis on which the question of hippocampal function can, at last, be sensibly debated; on that account alone their book is a very considerable achievement.

T.V.P. Bliss is a member of the Division of Neurophysiology and Neuropharmacology at the National Institute for Medical Research, London, UK.

\section{Nuclear and reactor physics concepts}

\section{Malcolm C. Scott}

A Guidebook to Nuclear Reactors. By A.V. Nero. (University of California Press: Berkeley, Los Angeles and London, 1979.) Hardback £17.50; paperback £5.95.

ALMOST without exception, nuclear power programmes throughout the world have been subjected to critical, and often hostile, scrutiny. There seems to be no single reason for these examinations; certainly, it is not related to the actual safety record of nuclear power reactors, as most re-appraisals predate the accident at the Three Mile Island pressurised water reactor plant at Harrisburg, Pennsylvania. Rather, the opposition to nuclear power has centered on a number of issues. The first of these is the relationship between nuclear power and the spread of nuclear weapons; the second relates to the problem of radioactive waste disposal and the associated question of whether or not we know enough about the effects of radiation; and the third is concerned not with nuclear power per se, but with the role of high technology in society.

To an interested but uninformed spectator some of the confrontations which have occurred must have seemed baffling. However, the worst aspect of this is possibly not the fact that 'experts' frequently hold diametrically opposite views but, rather, the fact that, as it is high technology, the whole field of nuclear power and radioactivity is relatively inaccessible. The few books written for the layman are too simplistic to allow an understanding of the issues involved (inasmuch as they are technical rather than sociological or political), whereas the specialist monographs are incomprehensible, assuming a background which the layman does not have. Even for professionals, much of the information required to counter opposition arguments is scattered through the literature, and there has been no single book giving the necessary background technical information across the whole nuclear front.

A Guidebook to Nuclear Reactors was written specifically to try and overcome these problems. It is intended for both the non-technically trained and the professional needing a wide ranging but concise guide to the whole nuclear power field.

The book is divided into four parts. The first, entitled "A General Introduction to Nuclear Reactors", starts by outlining the main features of a nuclear power plant and then goes on to consider the effect which such a system has on its surroundings, in terms of both heat and radioactivity discharges. At the end of this section there is a chapter on accidents, discussing how they can arise and what the consequences may be, and concluding with an introduction to risk assessment along the lines of the American Rasmussen Study.

In the second part there are four chapters, each dealing with a specific reactor type, namely pressurised water reactors, boiling water reactors, heavy water reactors and gas-cooled thermal reactors. Here each chapter has the same format, namely a description of the layout and principal components of each reactor type, followed by a description of auxiliary systems. Next comes a discussion of the safety systems incorporated in the reactor, and there is then consideration of fuel utilisation and reactor operation.

The third section, also of four chapters, starts off by considering the question of uranium resources and then goes on to discuss the role of both fast breeder reactors and high conversion efficiency thermal systems. The various nuclear fuel cycles are then outlined in the context of fuel processing, which leads naturally to a chapter on "The Weapons Connection". Finally, in the fourth section, there are three chapters on advanced reactor systems ("Breeders, Near-Breeders and What Not"'), the last chapter including a mention of fusion, fission-fusion and acceleratorbased nuclear fuel breeding systems.

Let it be said immediately that this is an extremely good book. However, the concentration on reactor systems found in, or of interest to, the United States means that systems in, for example, the USSR, together with our own in Britain, get scant mention ("In addition, England has constructed gas-cooled reactors with carbon dioxide coolant"'). There is some repetition, which may have a didactic purpose, and some Americanese ("The style of the book is more informational than argumentative"'), though mercifully little.

Nevertheless, faced with the abundance of extremely useful tables and figures, it is churlish to emphasise these faults. For the professional involved in nuclear debates and for the student entering the field this is an invaluable book. However, its value for the layman is likely to be limited by the sheer quantity of information and density of technical terms which, even when explained, need to be absorbed in order to appreciate the text. Nevertheless, as a source of background information for the non-scientist it remains the best book which I have seen, and Anthony Nero deserves credit for trying to raise the level of the so-called 'nuclear debate'.

Malcolm C. Scott is a Senior Lecturer in the Department of Physics at the University of Birmingham, UK, in charge of the MSc course on the Physics and Technology of Nuclear Reactors. 